\title{
Redox-Driven Chelation and Kinetic Separation of Select Rare Earths Using a Tripodal Nitroxide Proligand
}

Bren E. Cole ${ }^{\dagger}$ Thibault Cheisson, ${ }^{\dagger}$ Robert F. Higgins, ${ }^{\dagger}$ Eiko Nakamaru-Ogiso, ${ }^{\ddagger}$ Brian C. Manor, ${ }^{\dagger}$ Patrick J. Carroll, ${ }^{\dagger}$ and Eric J. Schelter ${ }^{\star \dagger}$

† P. Roy and Diana T. Vagelos Laboratories, Department of Chemistry, University of Pennsylvania, 231 S $34^{\text {th }}$ St., Philadelphia, Pennsylvania 19104, United States

‡ Department of Biochemistry and Biophysics, Perelman School of Medicine, University of Pennsylvania, Philadelphia, Pennsylvania, 19104, United States

*schelter@sas.upenn.edu

\section{Supporting Information}

ICP-OES Experimental Procedures

IR Spectra

${ }^{1} \mathrm{H}$ and Evans' Method NMR Spectra

Squid Magnetometry Data

EPR Simulation Data

Cyclic Voltammetry

Reaction of $\mathrm{La}\left(\mathrm{C}_{5} \mathrm{Me}_{4} \mathrm{H}\right)_{3}$ with 1 


\section{Experimental Procedures}

Inductively Coupled Plasma - Optical Emission Spectroscopy (ICP-OES)

Inductively coupled plasma optical emission spectroscopy was conducted on a Spectro Genesis ICP-OES spectrometer (SPECTRO Analytical Instruments GmbH, Kleve, Germany) equipped with an integrated three channel peristaltic pump and a ASX-260 auto-sampler (CETAC Technologies, Omaha, NE, USA). Samples solutions were delivered to the nebulizer using a Mod Lichte spray chamber and single-use PVC PT-2140PF tubing (Precision Glassblowing, Centennial, CO, USA). Each data acquisition was preceded by a 35 second rinse sequence at different pump speeds. Other relevant parameters were previously optimized to give the smallest RSD and are summarized in Table S1.

\section{Table S1. Instrumental and operating conditions for ICP-OES measurements}

\begin{tabular}{|c|c|}
\hline \multicolumn{2}{|l|}{ Instrument conditions } \\
\hline Forward power (W) & 1350 \\
\hline Plasma gas flow rate $\left(\mathrm{L} \min ^{-1}\right)$ & 13.50 \\
\hline Auxiliary gas flow rate $\left(L \mathrm{~min}^{-1}\right)$ & 1.00 \\
\hline Nebulizer flow rate $\left(\mathrm{L} \min ^{-1}\right)$ & 0.90 \\
\hline Wavelengths (nm) & $\begin{array}{l}\text { La } 333.749 \\
\text { Y } 442.259\end{array}$ \\
\hline
\end{tabular}

Nitric acid (Fisher, Certified ACS Plus grade), hydrogen peroxide (Fisher, 30\% solution in water), and distilled-deionized water (Milli-Q, $18.2 \mathrm{M} \Omega . \mathrm{cm}$, Millipore) were used for sample preparation and dilution. Samples were prepared by digestion in a (4:1) $\mathrm{HNO}_{3}: \mathrm{H}_{2} \mathrm{O}_{2}$ mixture at $100{ }^{\circ} \mathrm{C}$ for 1 hour, followed by dilution to a concentration of $\mathrm{ca} .5 \% \mathrm{HNO}_{3}$ to limit matrix effects. Analytical plasma standard solutions were obtained from Alfa Aesar (Specpure®, 1000 ppm $\mathrm{RE}_{2} \mathrm{O}_{3}$ in $5 \% \mathrm{HNO}_{3}$ ).

Calibrations were performed before each set of measurements using a range of 7 standardized solutions (125-0.025 ppm). Calibration curves were confirmed to have $R^{2}>0.999$ for the selected elements. Potential instrumental drift was monitored by continuously measuring $\mathrm{Ar}$ lines at 430.010 and $404.442 \mathrm{~nm}$; absence of drift was finally confirmed by measuring a standardized solution at the end of each measurement session. The following wavelengths $(\mathrm{nm})$ were used for element quantifications and reviewed for the absence of interferences: 333.749 (La), 442.259 (Y). The wavelengths selected had the highest signal intensity, in agreement with the literature, ${ }^{1}$ and were the most relevant for the studied range of concentrations. 
IR Spectroscopy

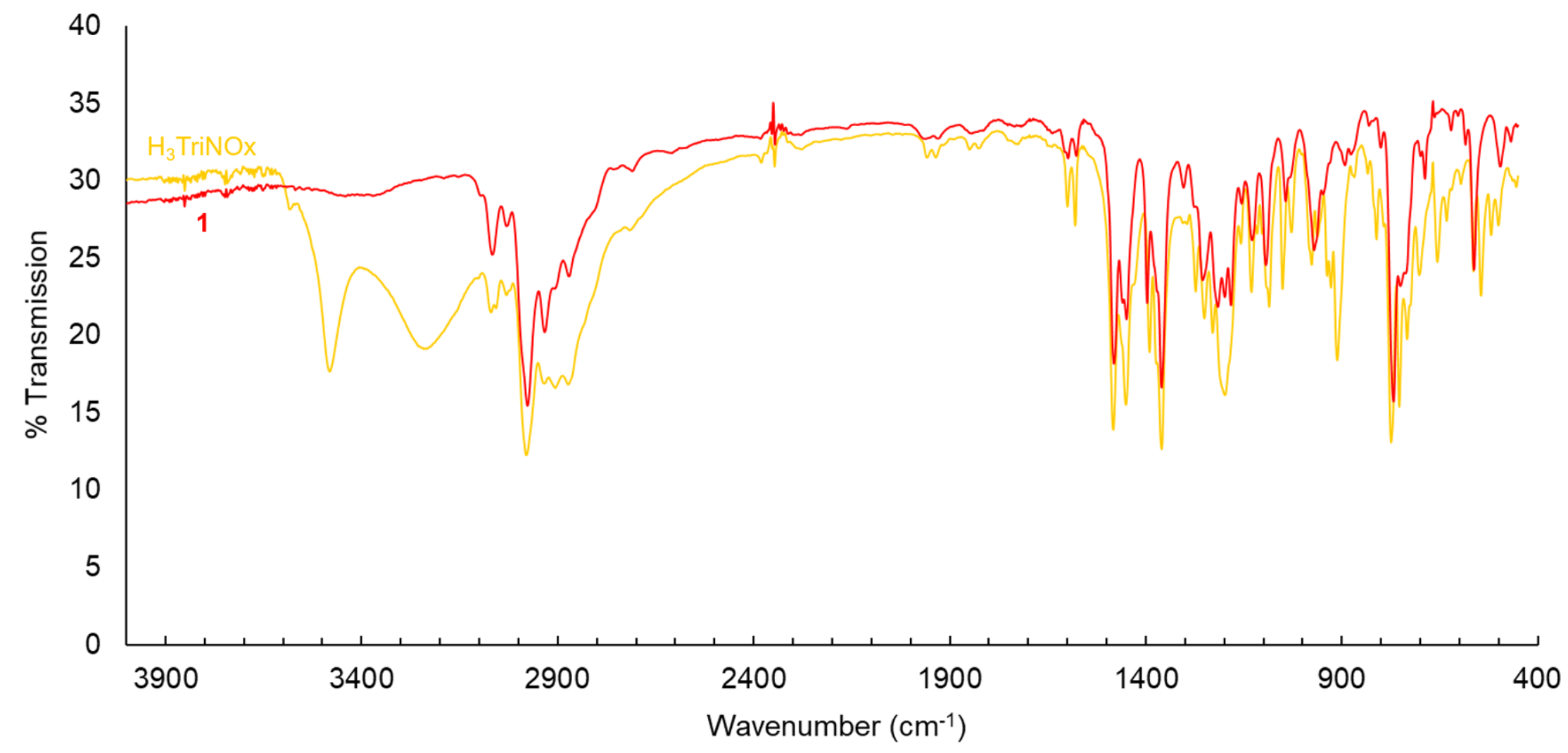

Figure S1. Infrared spectrum of $\mathrm{H}_{3}$ TriNOx (yellow trace) and $\mathbf{1}$ (red trace). 
${ }^{1} \mathrm{H}$ NMR Spectroscopy

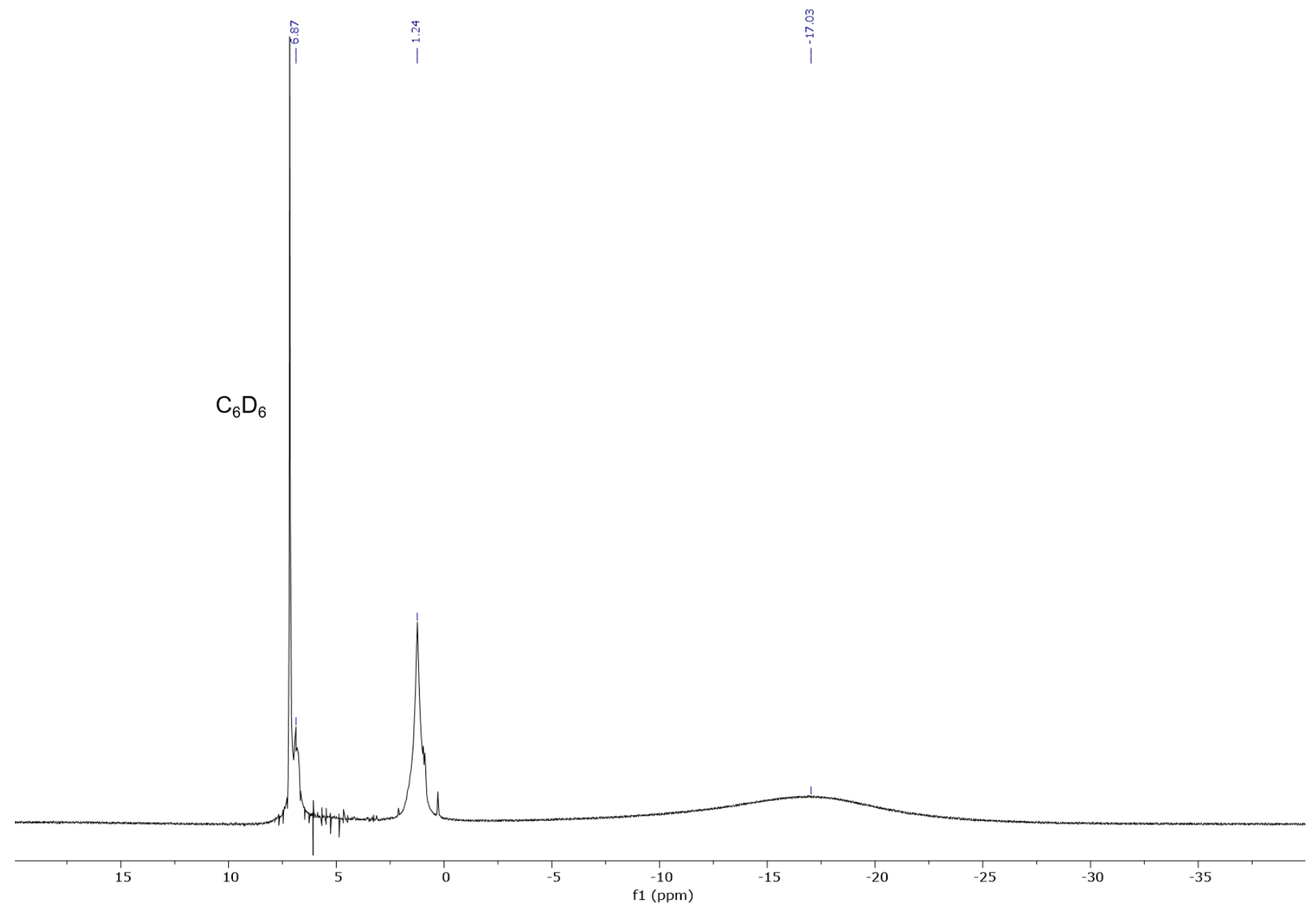

Figure S2. ${ }^{1} \mathrm{H}$ NMR spectrum of 1 in $\mathrm{C}_{6} \mathrm{D}_{6}$. 


\section{Evans' Method Experiments}

A sample of $10.0 \mathrm{mg}(0.02 \mathrm{mmol}) 1$ and $25 \mu \mathrm{L}$ mesitylene in $750 \mu \mathrm{L} \mathrm{C}_{6} \mathrm{D}_{6}$ was prepared in an NMR tube. A stock solution of $25 \mu \mathrm{L}$ mesitylene in $750 \mu \mathrm{L} \quad \mathrm{C}_{6} \mathrm{D}_{6}$ was added to a centrosymmetric capillary tube placed inside the NMR tube. Sample measured on a Bruker DMX-500 Fourier transform NMR spectrometer while operating at a ${ }^{1} \mathrm{H}$ frequency of $500 \mathrm{MHz}$. The room temperature, solution phase magnetic susceptibility value was calculated based upon the observed chemical shifts from the mesitylene standard.

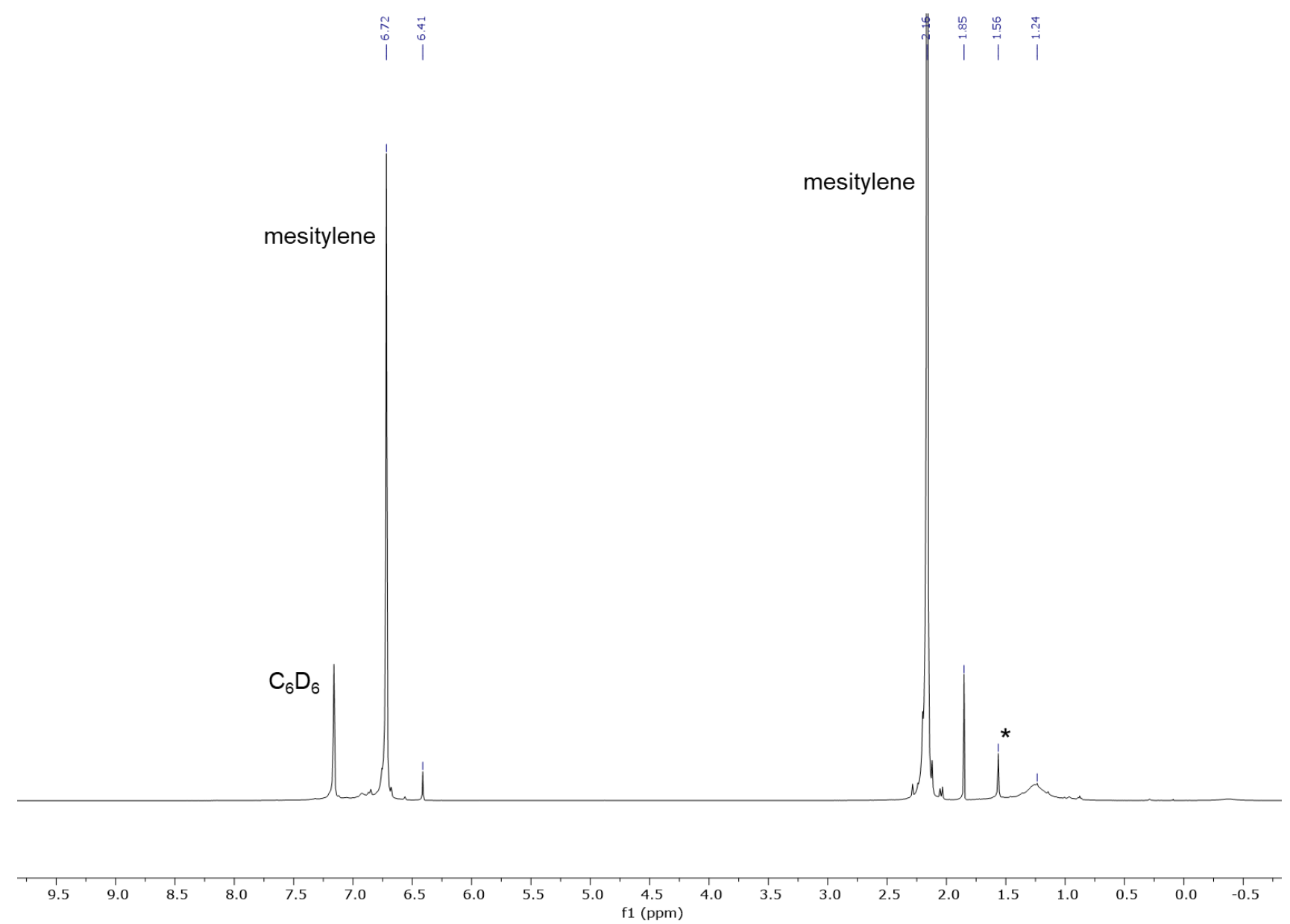

Figure S3. Evans' Method ${ }^{1} \mathrm{H}$ NMR Spectrum in $\mathrm{C}_{6} \mathrm{D}_{6} .{ }^{*}$ indicates acetone solvent impurity. 


\section{SQUID Magnetometry Data}

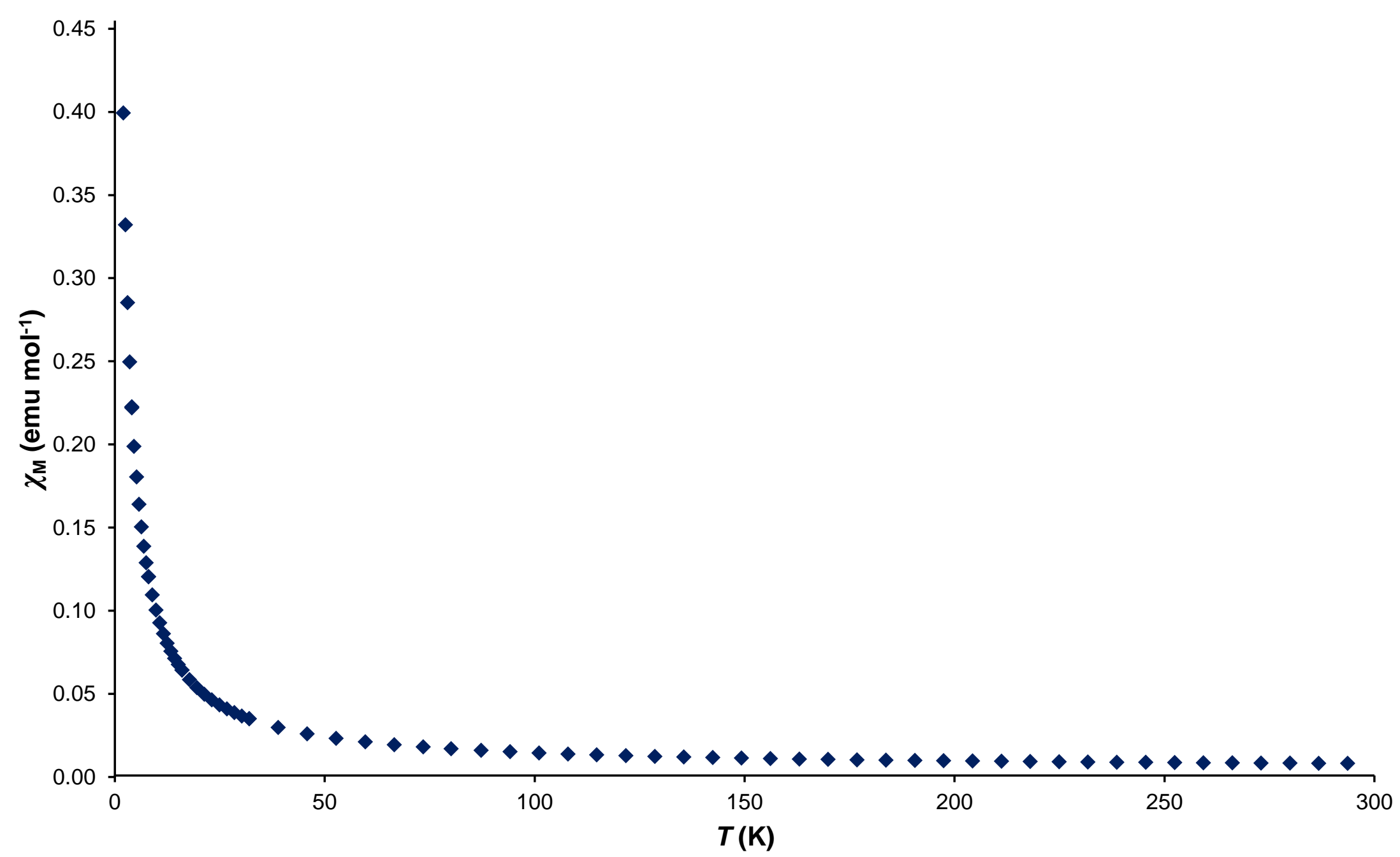

Figure S4. $\chi_{M}$ vs $T$ plot of 1 from $2 \mathrm{~K}$ to $300 \mathrm{~K}$. 


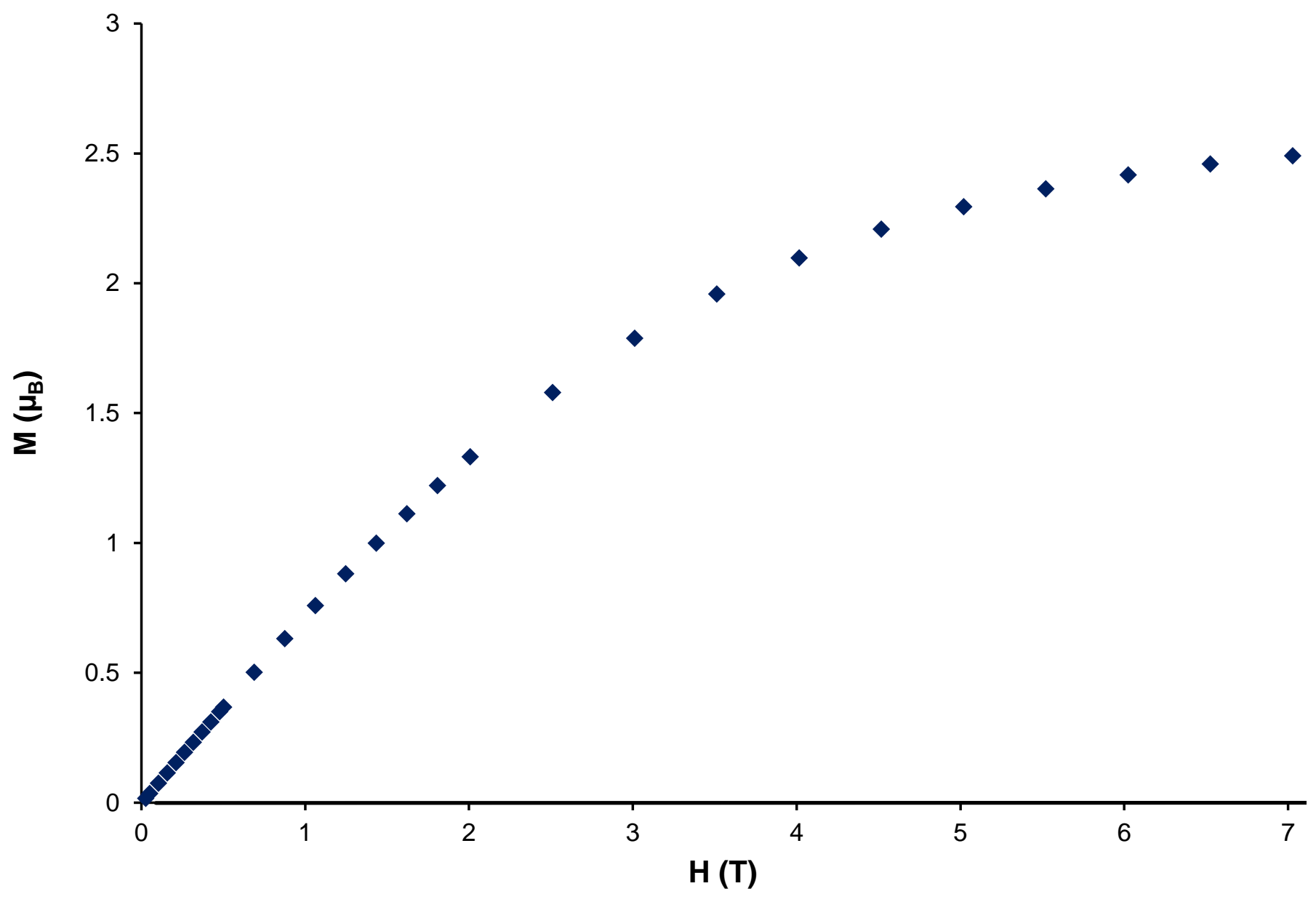

Figure S5. M vs $\mathrm{H}$ of 1 from $0 \mathrm{~T}$ to $7 \mathrm{~T}$ at $2 \mathrm{~K}$. 


\section{EPR Spectroscopy}

The reported spin Hamiltonian for a tri-radical is described by:2

$$
\begin{aligned}
& H=g \beta_{e} B\left(S_{Z}{ }^{(1)}+S_{Z}{ }^{(2)}+S_{Z}{ }^{(3)}\right)+a\left(S_{Z}{ }^{(1)} \cdot I_{Z}{ }^{(1)}+S_{Z}{ }^{(2)} \cdot I_{z}{ }^{(2)}+S_{Z}{ }^{(3)} \cdot I_{Z}{ }^{(3)}\right)+J_{12}\left(S_{Z}{ }^{(1)} \cdot S_{Z}{ }^{(2)}\right) \\
& +J_{23}\left(S_{Z}^{(2)} \cdot S_{Z}{ }^{(3)}\right)+J_{13}\left(S_{Z}^{(1)} \cdot S_{Z}^{(3)}\right)
\end{aligned}
$$

The solid-state data demonstrated a broad signal centered at $g=2.00746$.

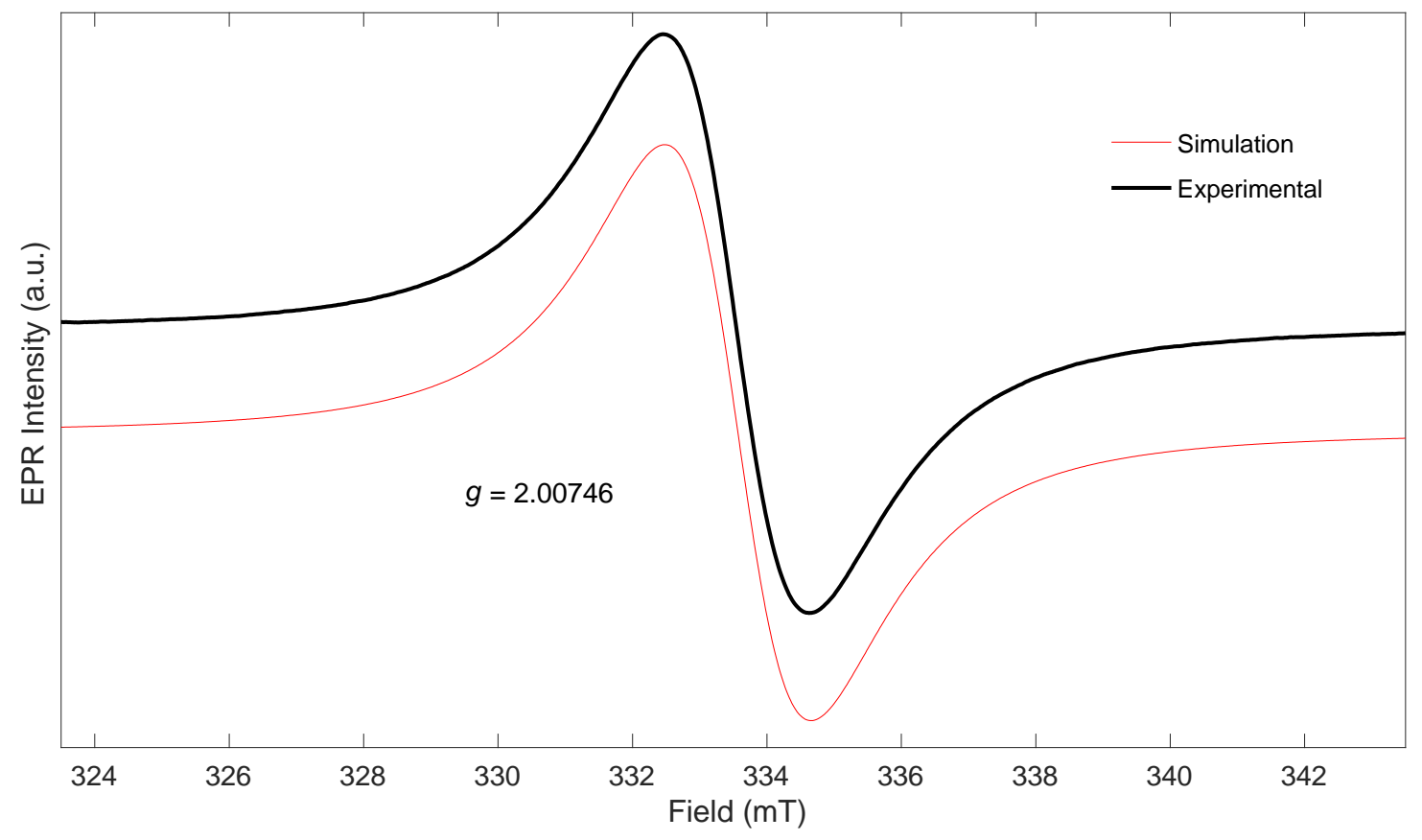

Figure S6. Solid-state EPR spectrum (black trace) of 1 at $298 \mathrm{~K}$ and simulation (red trace).

For the solution-state data, two different models were considered:

- The experimental EPR data were fitted using a two-component spin system composed of: (1) isolated spins $\left(J \sim 0\right.$, three lines), (2) spin-exchange between two spins $\left(J>a_{N}\right.$, five lines). The results of the simulation are presented in the main text. The following parameters were obtained from the simulation:

\begin{tabular}{lll}
\hline Parameters & 3 lines & 5 lines \\
\hline$g$ & 2.0082 & 2.0084 \\
$a_{N}(\mathrm{G})$ & 13.80 & 6.20 \\
weight $(\%)$ & 32.9 & 67.1
\end{tabular}


- A second model was considered using a two-component spin system composed of: (1) isolated spins ( $J \sim 0$, three lines), (2) spin-exchange between three spins $\left(J>a_{N}\right.$, seven lines). The following fit and parameters were obtained from the simulation:

\begin{tabular}{lll}
\hline Parameters & 3 lines & 7 lines \\
\hline$g$ & 2.0082 & 2.0086 \\
$a_{N}(\mathrm{G})$ & 13.16 & 6.08 \\
weight $(\%)$ & 24.7 & 75.3
\end{tabular}

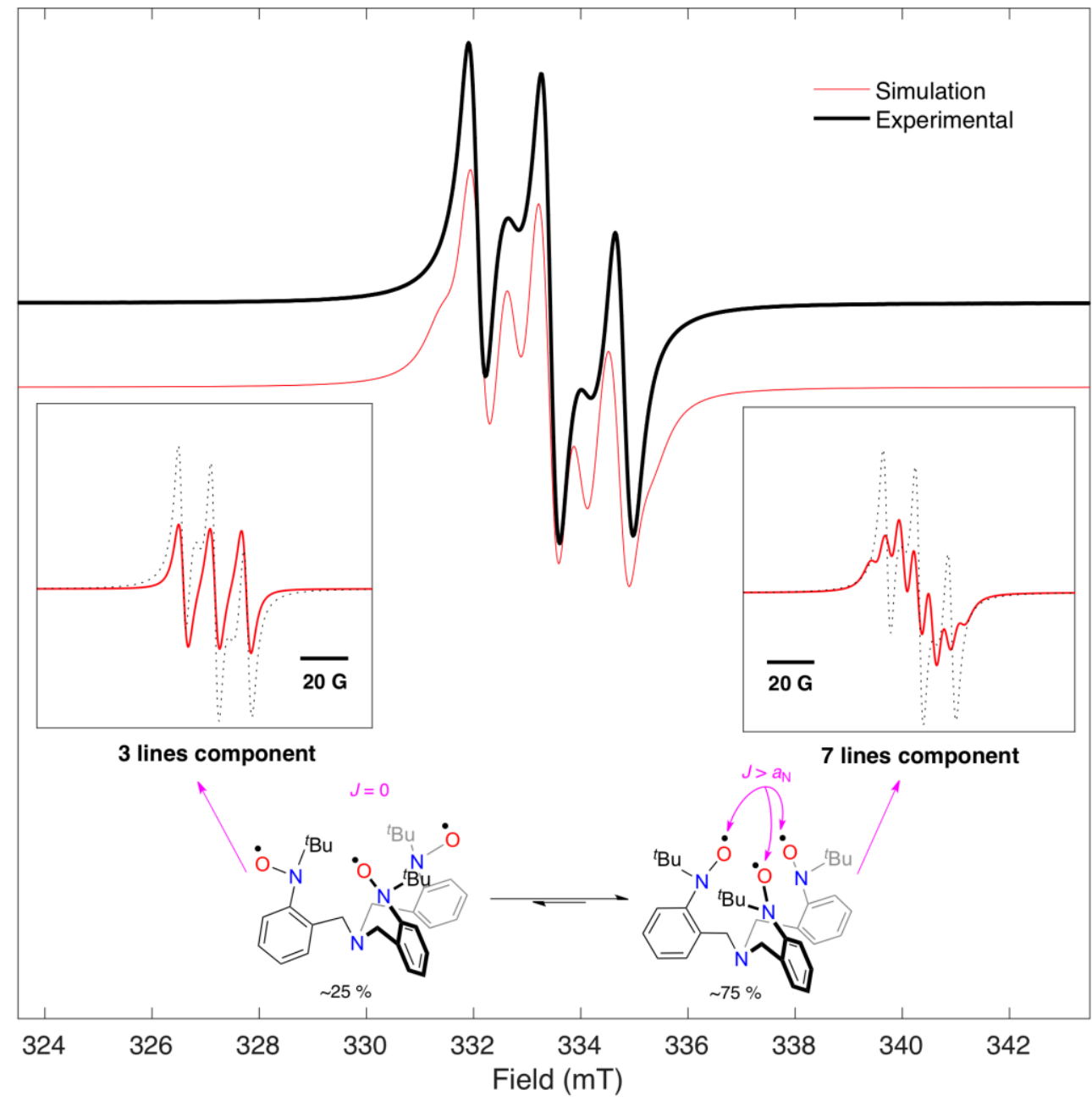

Figure S7. Experimental (black traces) and simulated (red traces) for the second possible spin system involving the exchange between an "open" form (3-line component) and a "closed" form (7-line component). 


\section{Cyclic Voltammetry of 1}

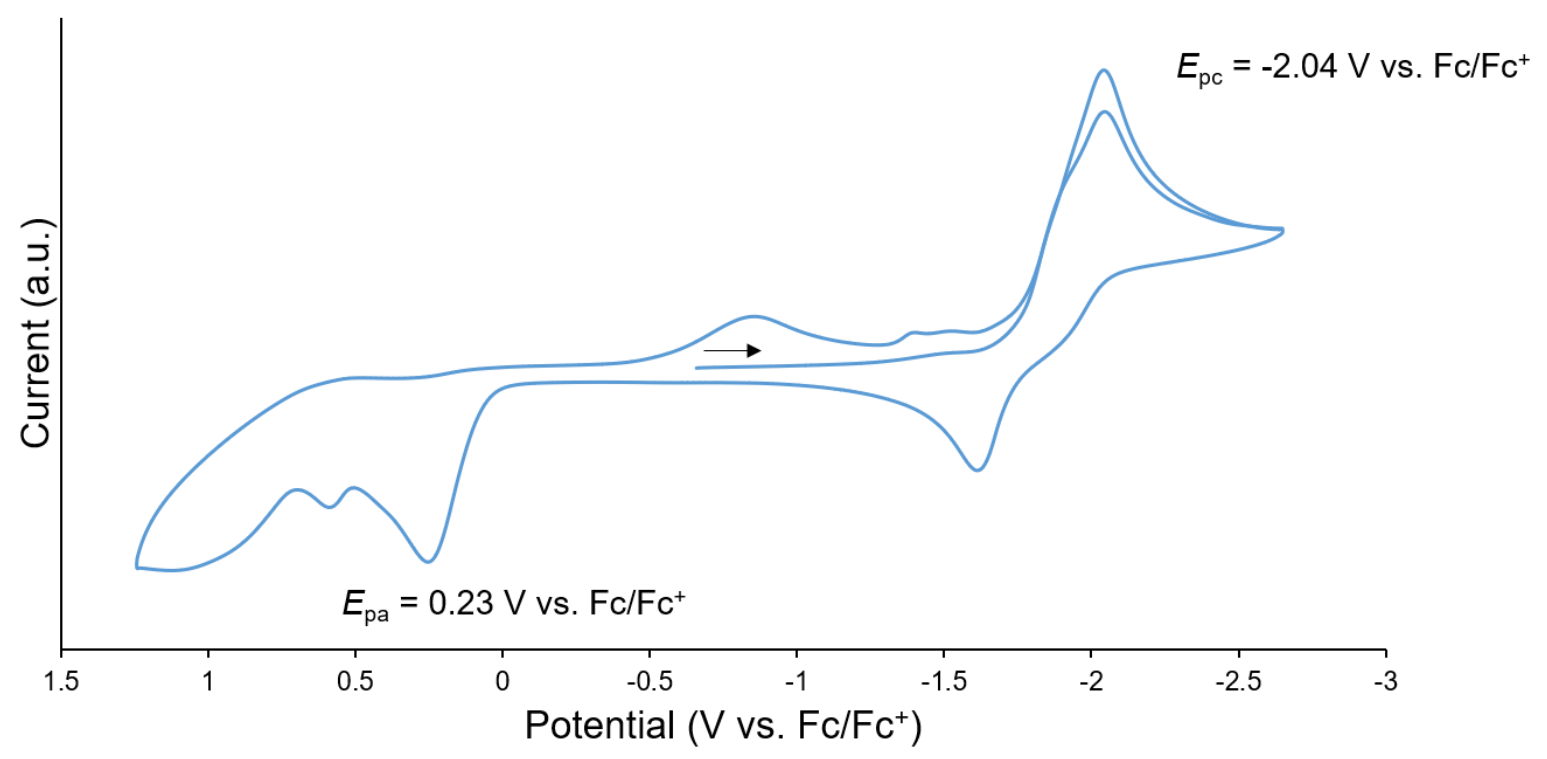

Figure S8. Cyclic voltammogram of 1 recorded at a scan rate of $100 \mathrm{mV} / \mathrm{s}$ in $0.1 \mathrm{M}$ $\left[{ }^{n} \mathrm{Pr}_{4} \mathrm{~N}\right]\left[\mathrm{BAr}_{4}\right]$ THF solution. 


\section{Reaction of $\mathrm{La}\left(\mathrm{C}_{5} \mathrm{Me}_{4} \mathrm{H}\right)_{3}$ with 1}

A $2 \mathrm{~mL}$ THF solution of 1 (102.4 $\mathrm{mg}, 0.185 \mathrm{mmol}$ ) was added to a THF suspension (1 $\mathrm{mL})$ of $\mathrm{La}\left(\mathrm{C}_{5} \mathrm{Me}_{4} \mathrm{H}\right)_{3}(94.2 \mathrm{mg}, 0.185 \mathrm{mmol})$ and stirred 5 minutes. The yellow suspension was filtered to yield $97.6 \mathrm{mg}(0.129 \mathrm{mmol})$ of $\mathrm{La}($ TriNOx $)(\mathrm{THF})$ as a white solid (70\% yield). Assignment of $\left({ }^{\mathrm{Me}} \mathrm{Cp}\right)_{2}$ peaks was determined according to literature precedent. ${ }^{3}$
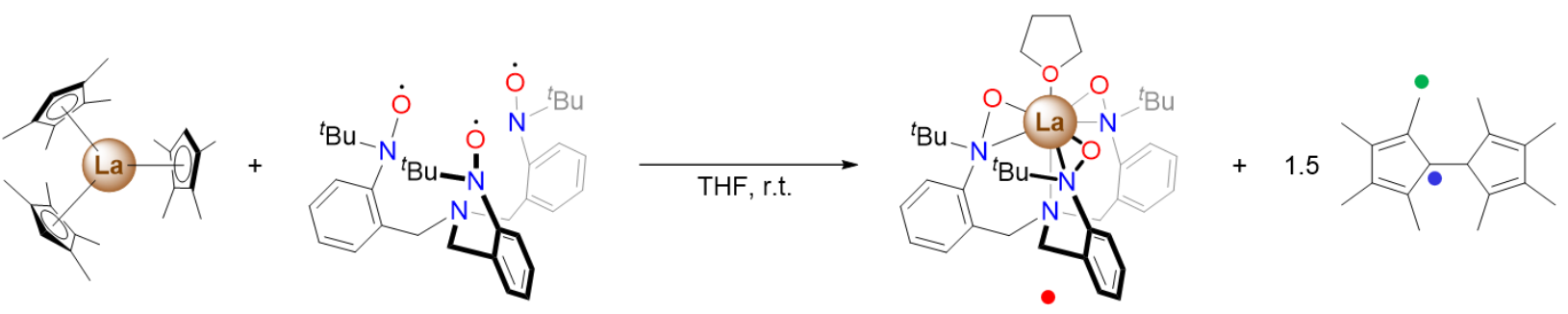

Scheme S1. Reaction of 1 with lanthanum(III)-tris(tetramethylcyclopentadienide).

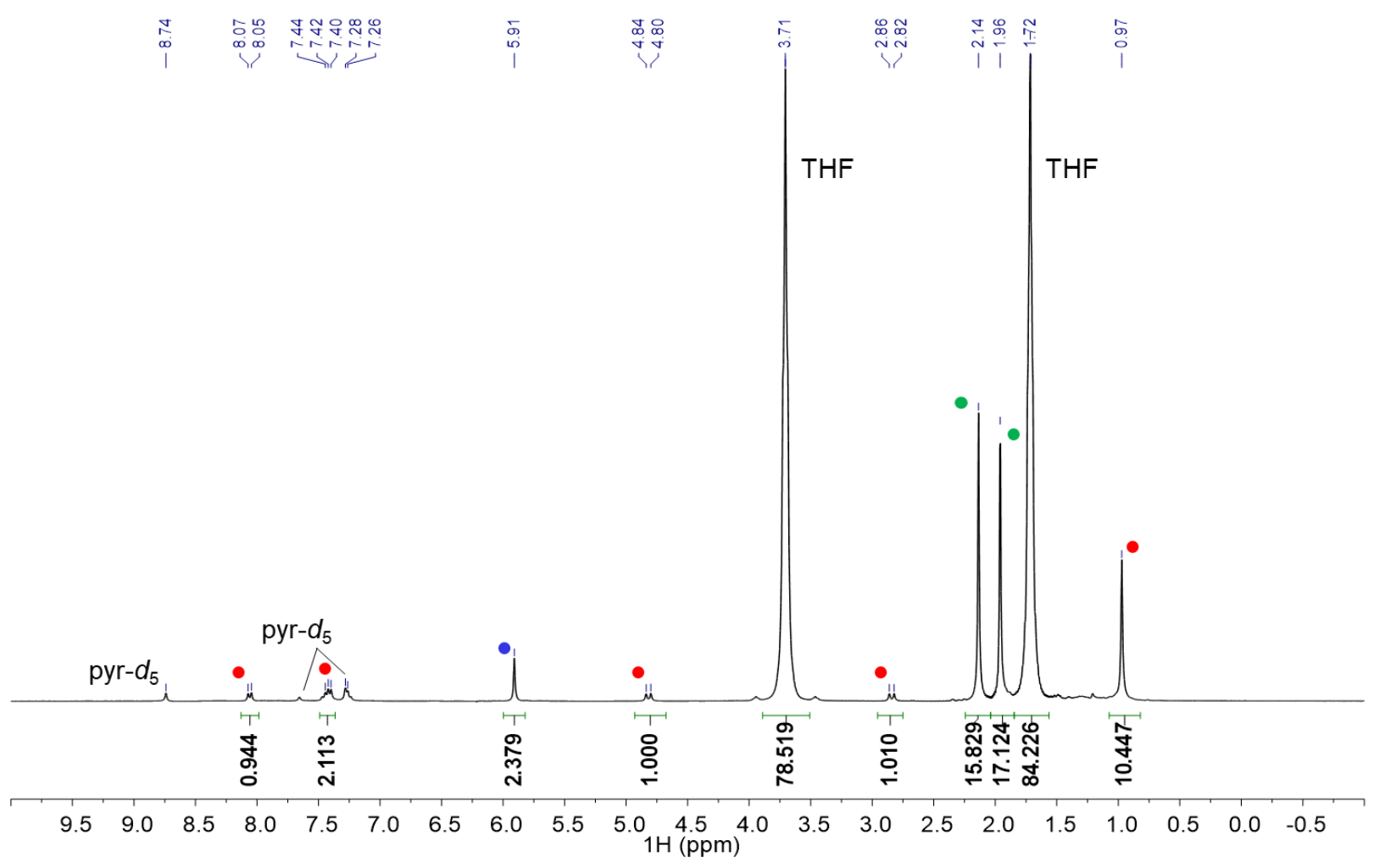

Figure S9. ${ }^{1} \mathrm{H}$ NMR spectrum of reaction mixture of $\mathrm{La}\left(\mathrm{C}_{5} \mathrm{Me}_{4} \mathrm{H}\right)_{3}$ and 1 in pyridine- $d_{5}$. 


\section{$\operatorname{RE}(\mathrm{Cp})_{3}$ Reaction with 1. Kinetic Experiments}

The reaction of $\operatorname{RE}(\mathrm{Cp})_{3}(0.030 \mathrm{mmol})$ and $1(0.030 \mathrm{mmol})$ in pyridine $-d_{5}(0.75 \mathrm{~mL})$ was monitored by ${ }^{1} \mathrm{H}$ NMR against an internal standard, 1,3,5-trimethoxybenzene $(0.030 \mathrm{mmol})$, at various timepoints. The concentration of $R E(C p)_{3}$ and $R E(T r i N O x)(p y r)$ was measured by integration and comparison to that of the internal standard. Dummy scans before NMR data collection were removed to ensure accurate timepoints were achieved.

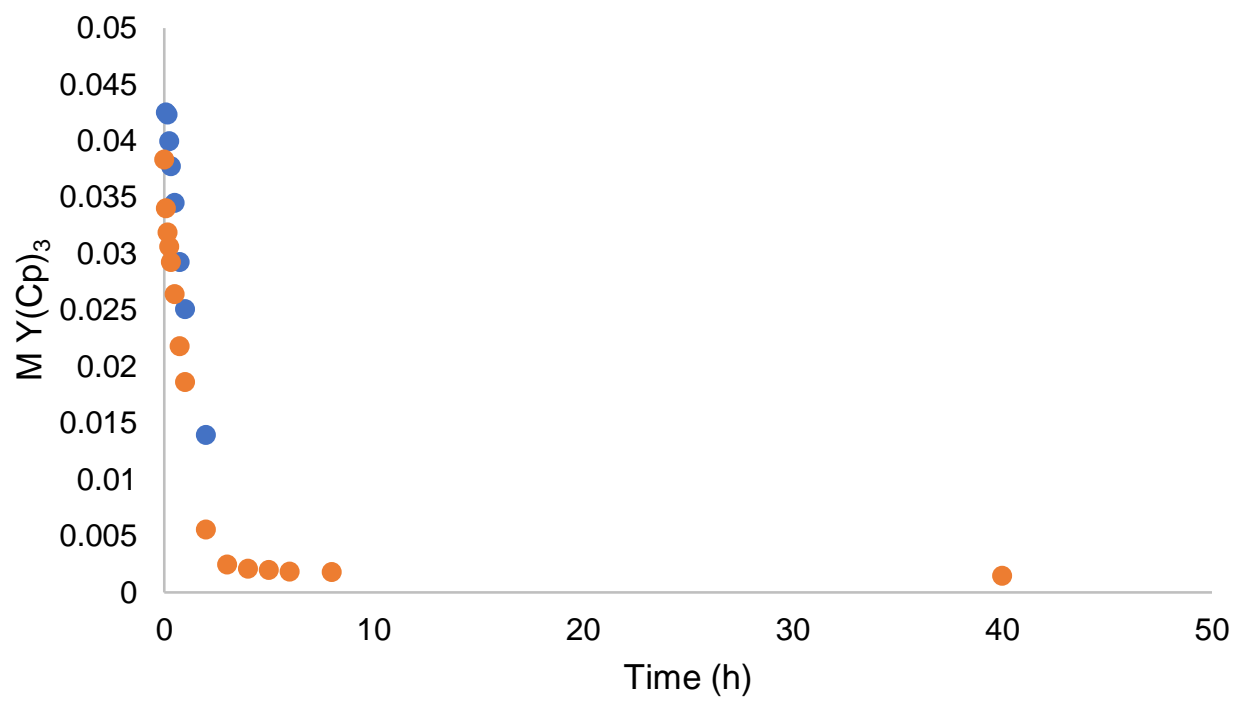

Figure S10. Concentration of $\mathrm{Y}(\mathrm{Cp})_{3}$ vs. Time plot, run 1 (orange) and run 2 (blue).

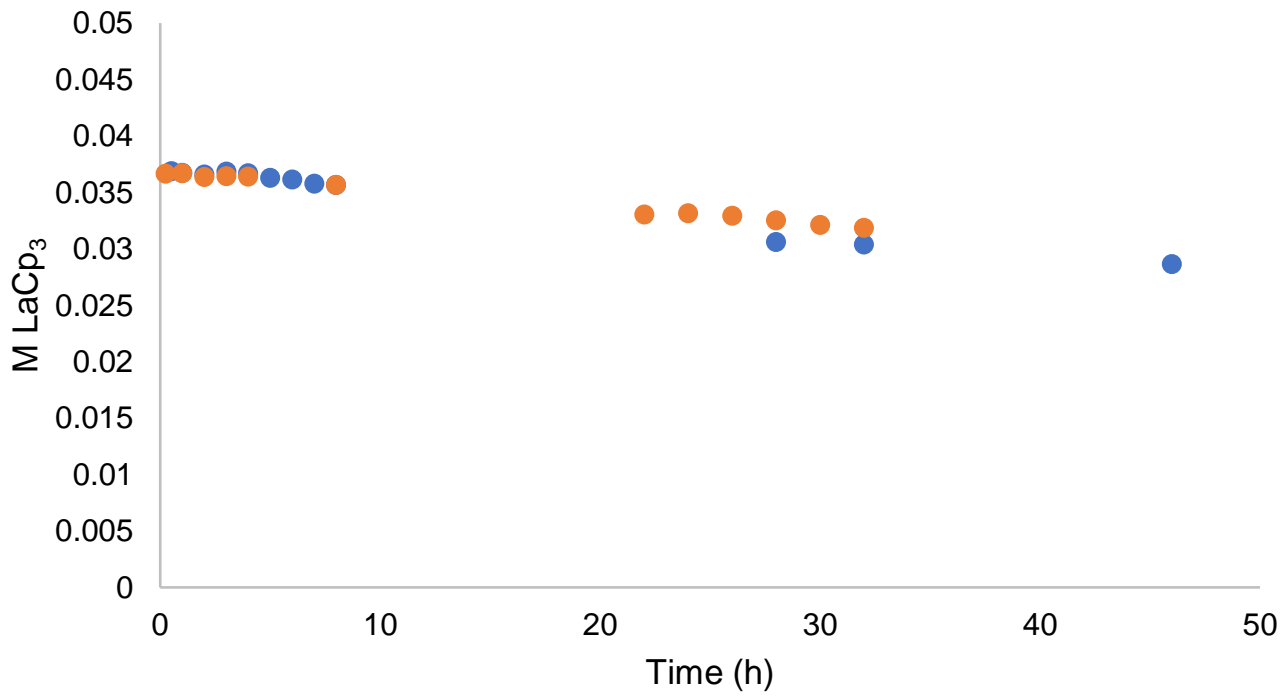

Figure S11. Concentration of $\mathrm{La}(\mathrm{Cp})_{3}$ vs. Time plot, run 1 (orange) and run 2 (blue). 


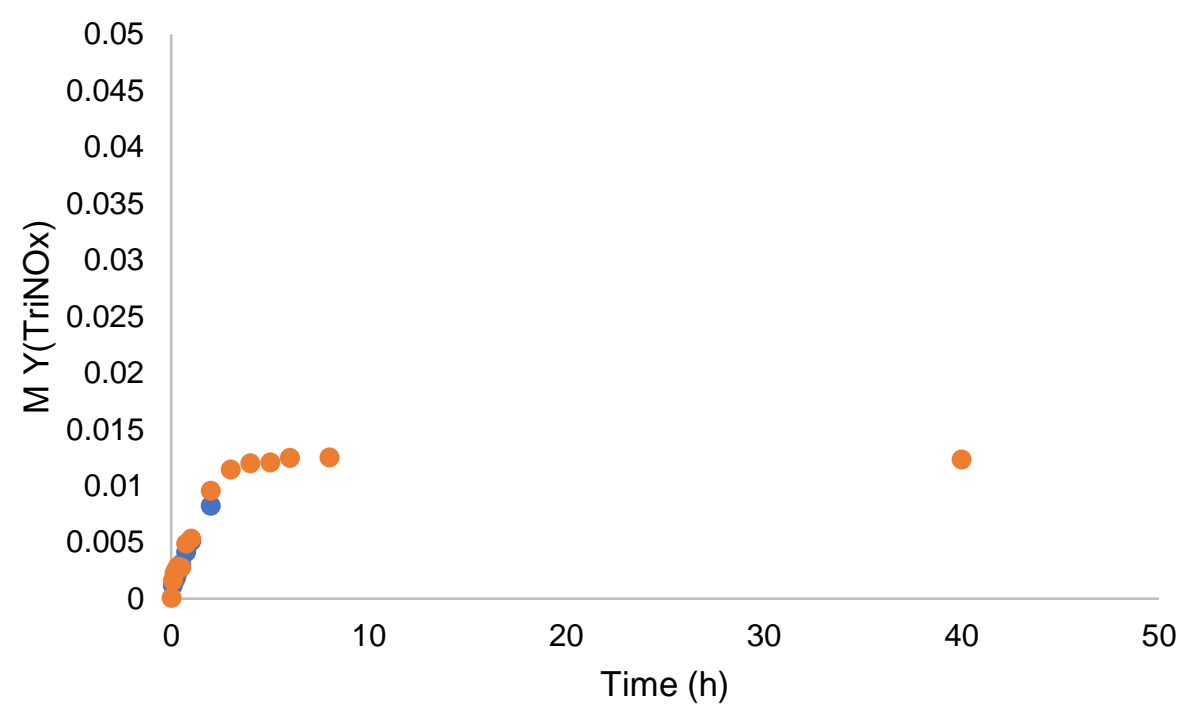

Figure S12. Concentration of Y(TriNOx) vs. Time plot, run 1 (orange) and run 2 (blue).

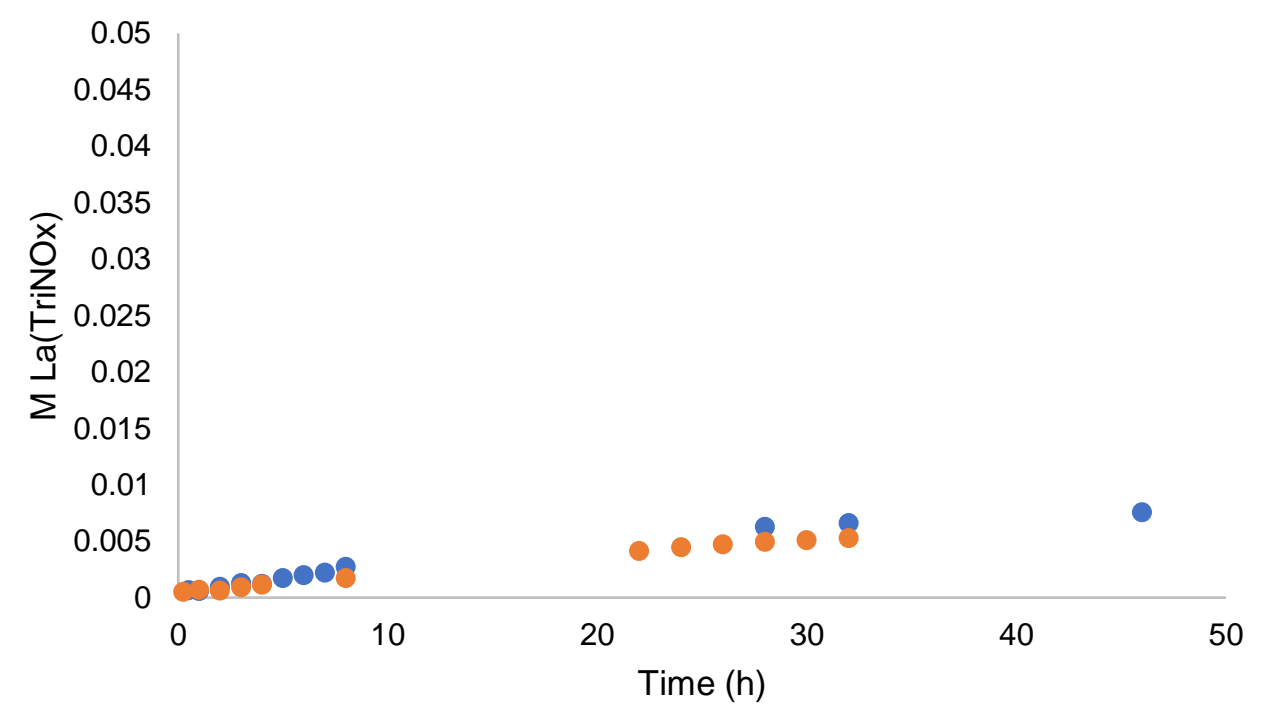

Figure S13. Concentration of La(TriNOx) vs. Time plot, run 1 (orange) and run 2 (blue). 


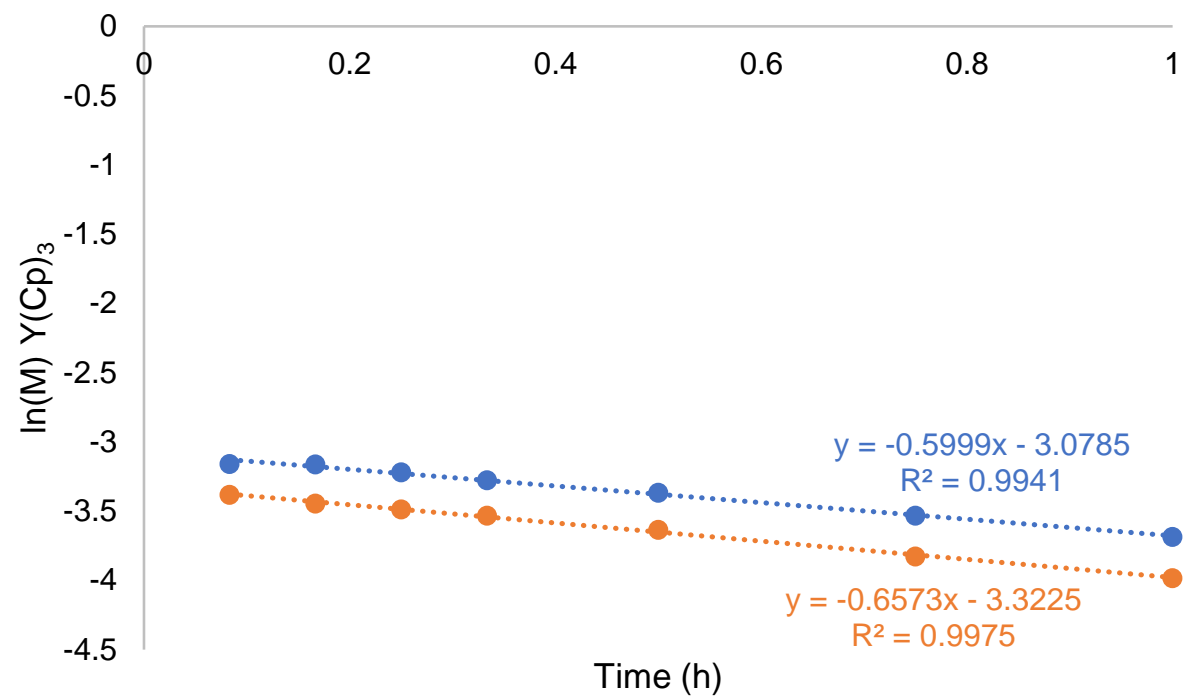

Figure S14. Concentration of $\operatorname{In}\left(\mathrm{Y}(\mathrm{Cp})_{3}\right)$ vs. Time plot, run 1 (orange) and run 2 (blue).

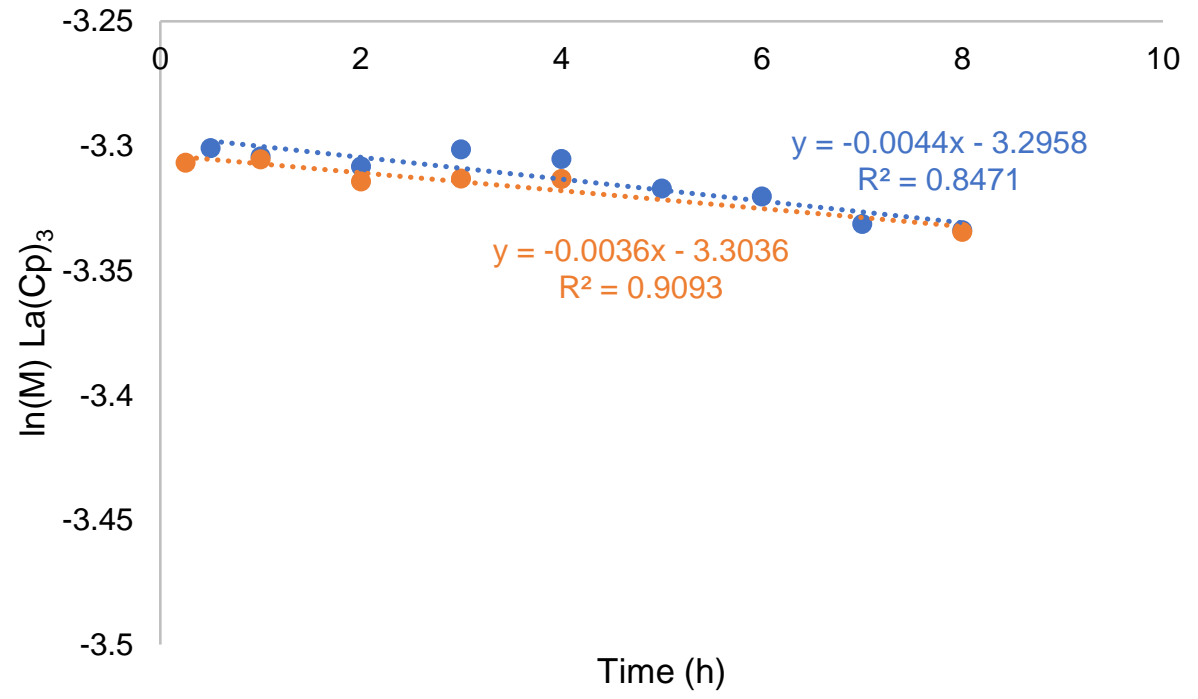

Figure S15. Concentration of $\ln \left(\operatorname{La}(\mathrm{Cp})_{3}\right)$ vs. Time plot, run 1 (orange) and run 2 (blue). 


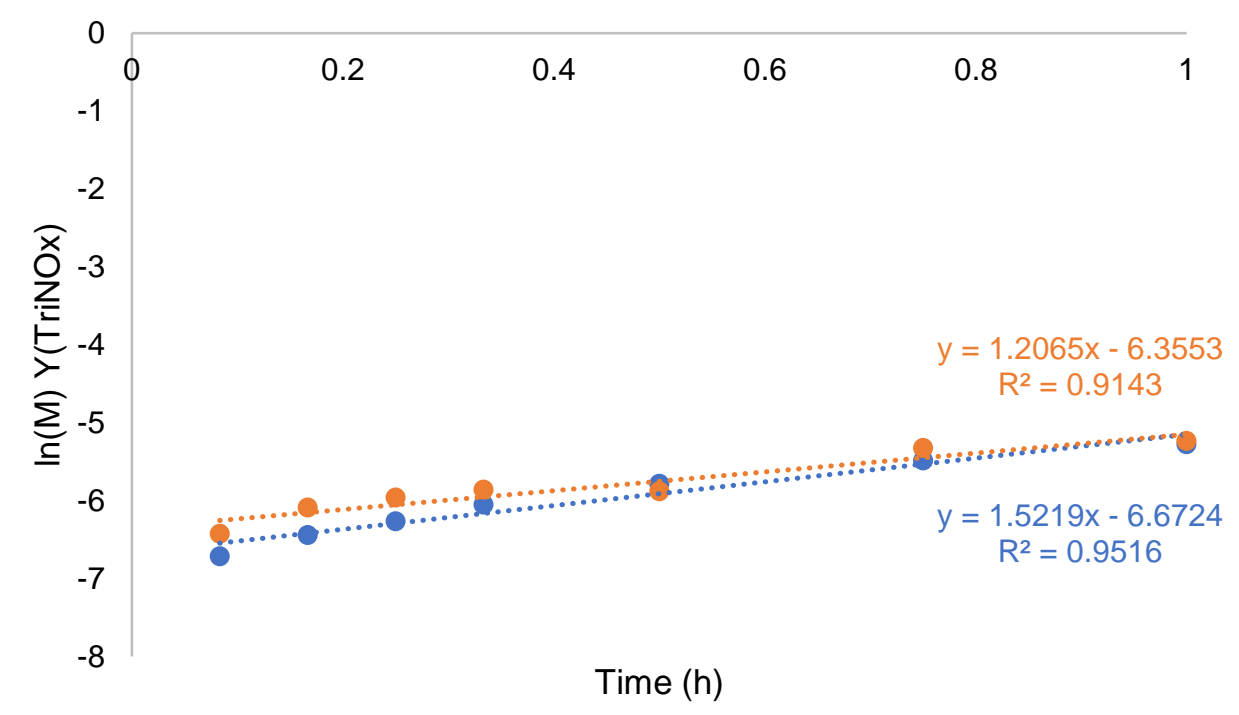

Figure S16. Concentration of $\ln [Y(T r i N O x)]$ vs. Time plot, run 1 (orange) and run 2 (blue).

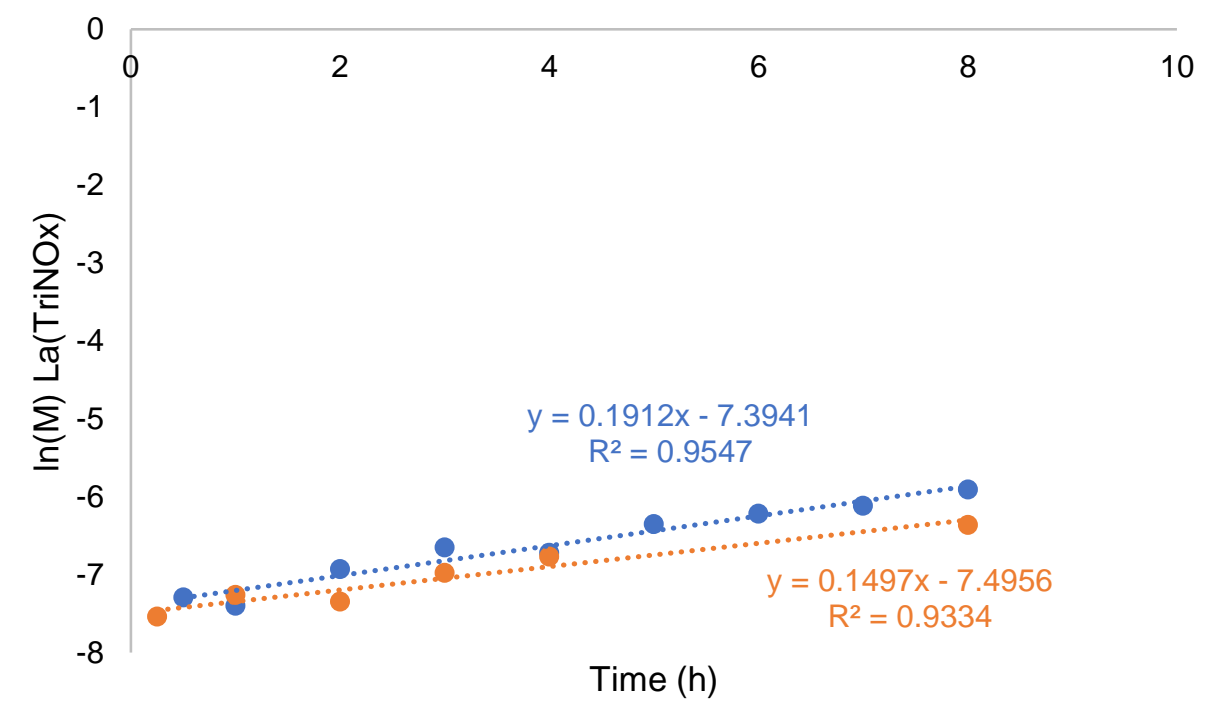

Figure S17. Concentration of $\ln [\operatorname{La}(\operatorname{TriNOx})]$ vs. Time plot, run 1 (orange) and run 2 (blue). 


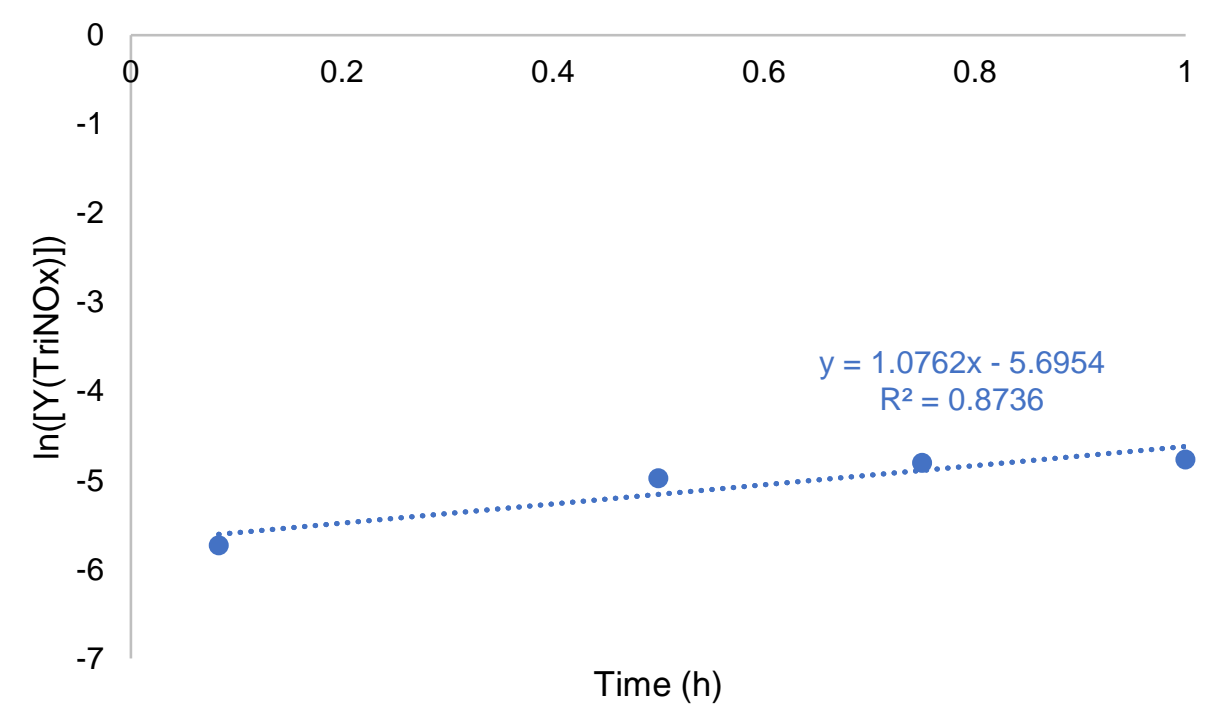

Figure S18. Concentration of $\ln ([Y(T r i N O x)])$ vs. Time plot under pseudo-first order $Y(C p)_{3}$ conditions.

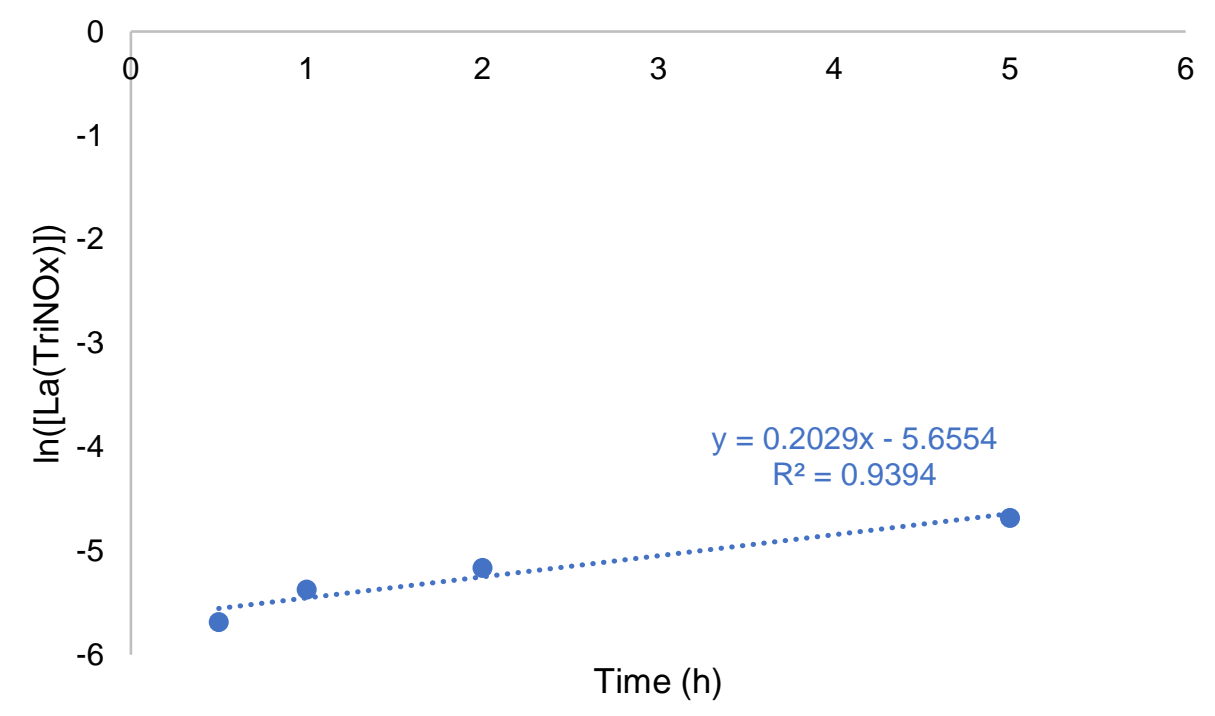

Figure S19. Concentration of $\operatorname{In}([\mathrm{La}(\operatorname{TriNOx})])$ vs. Time plot under pseudo-first order $\mathrm{La}(\mathrm{Cp})_{3}$ conditions. 


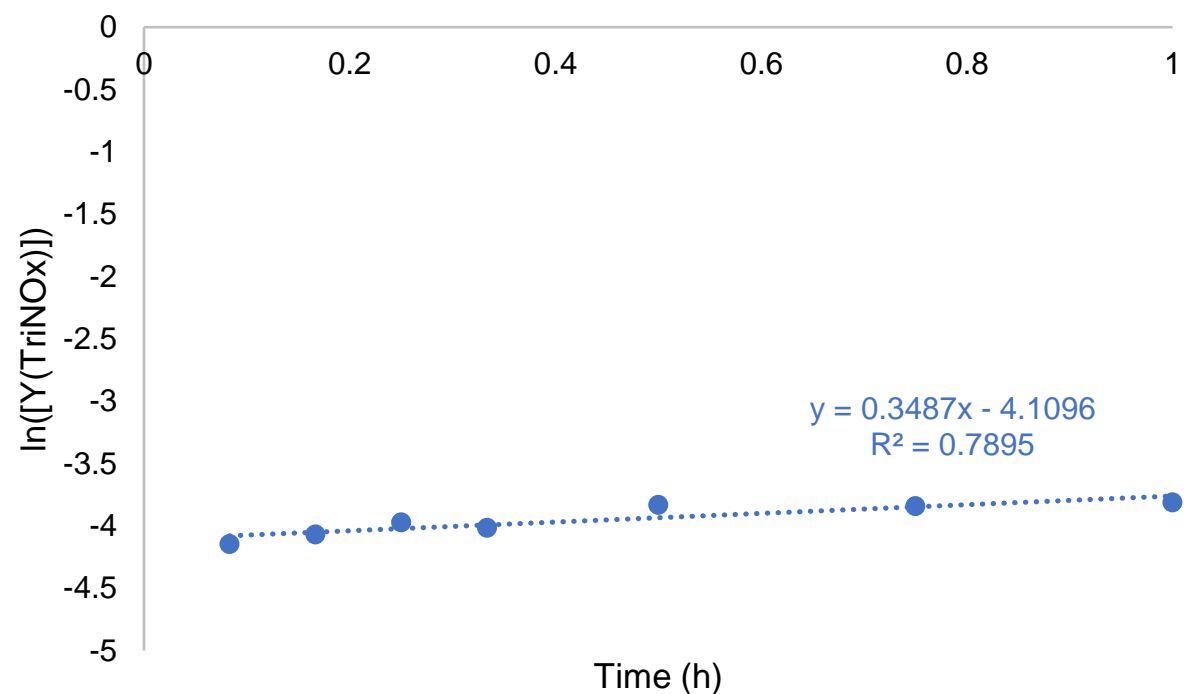

Figure S20. Concentration of $\ln ([Y(T r i N O x)])$ vs. Time plot under pseudo-first order of $\mathbf{1}$ conditions.

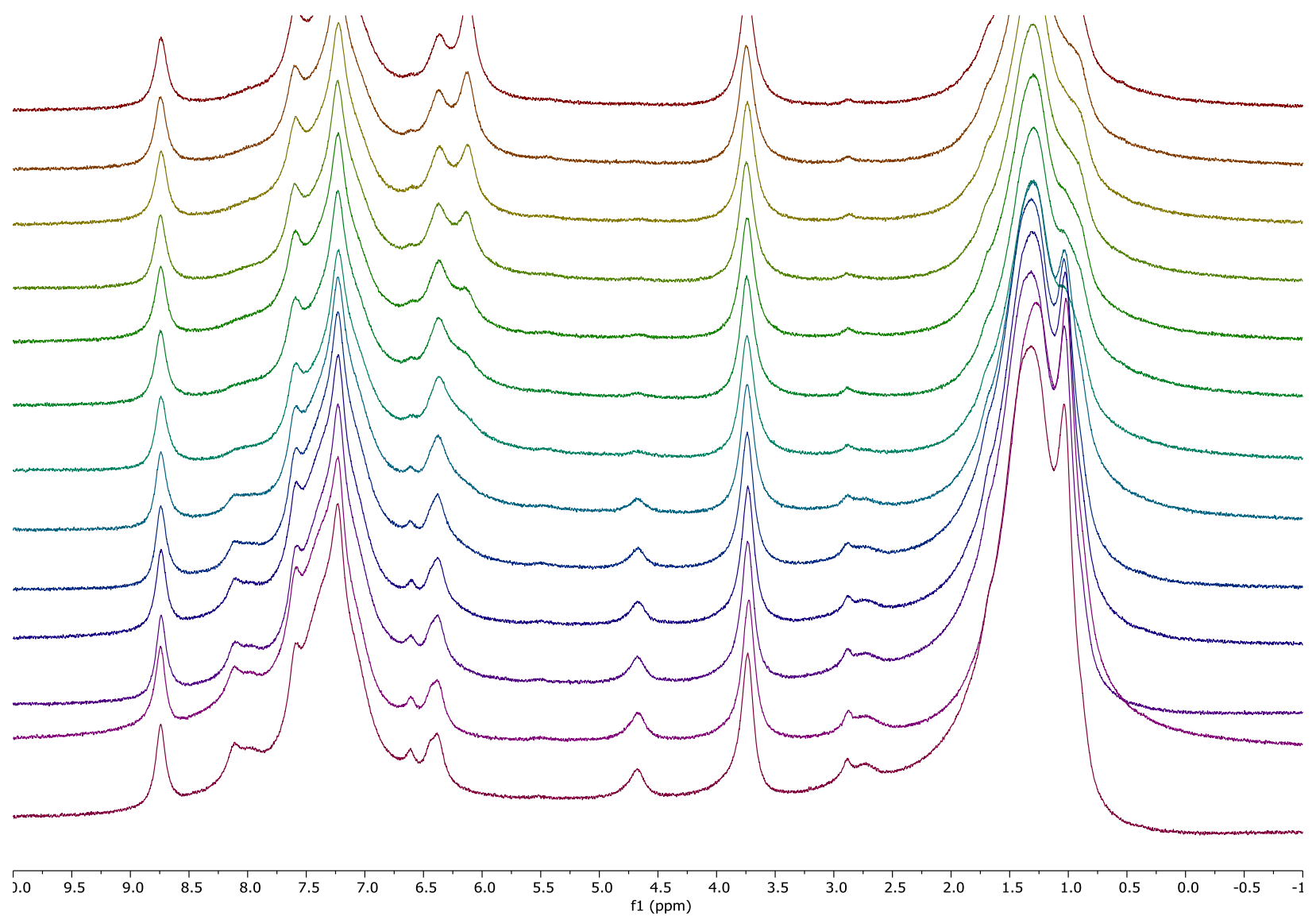

Figure S21. Example of ${ }^{1} \mathrm{H}$ NMR spectra of $\mathrm{Y}(\mathrm{Cp})_{3}$ reduction of 1 in the presence of a tenfold excess of 1 . Signals are too broad for reliable peak integration. 


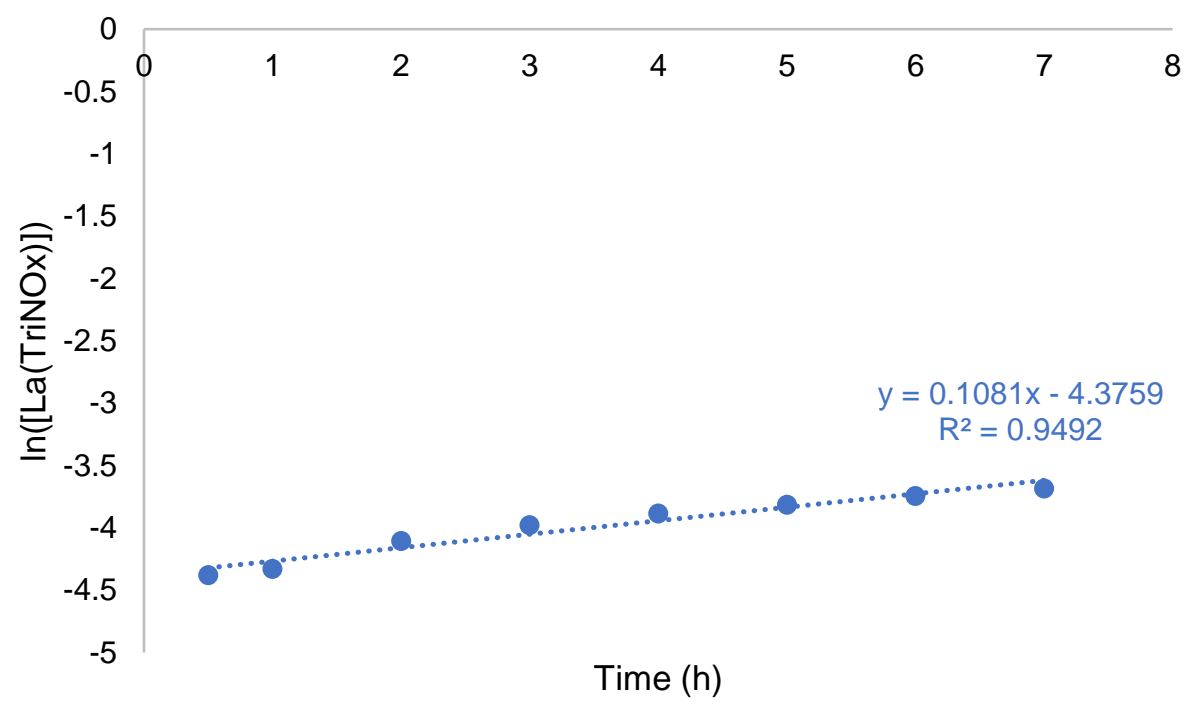

Figure S22. Concentration of $\ln ([\operatorname{La}(\operatorname{TriNOx})])$ vs. Time plot under pseudo-first order of $\mathbf{1}$ conditions.

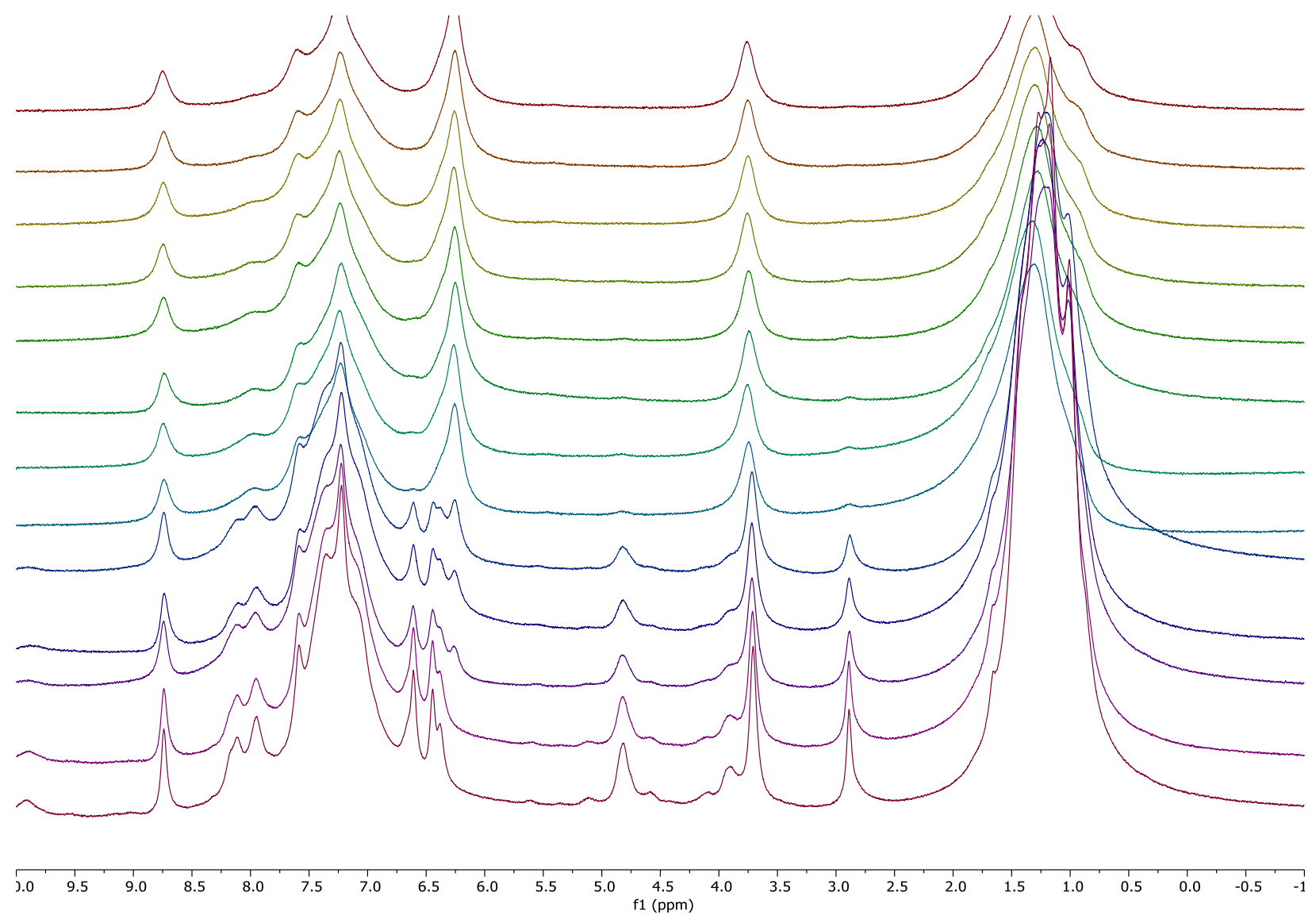

Figure S23. Example of ${ }^{1} \mathrm{H}$ NMR spectra of $\mathrm{La}(\mathrm{Cp})_{3}$ reduction of $\mathbf{1}$ in the presence of a tenfold excess of 1 . Signals are too broad for reliable peak integration. 


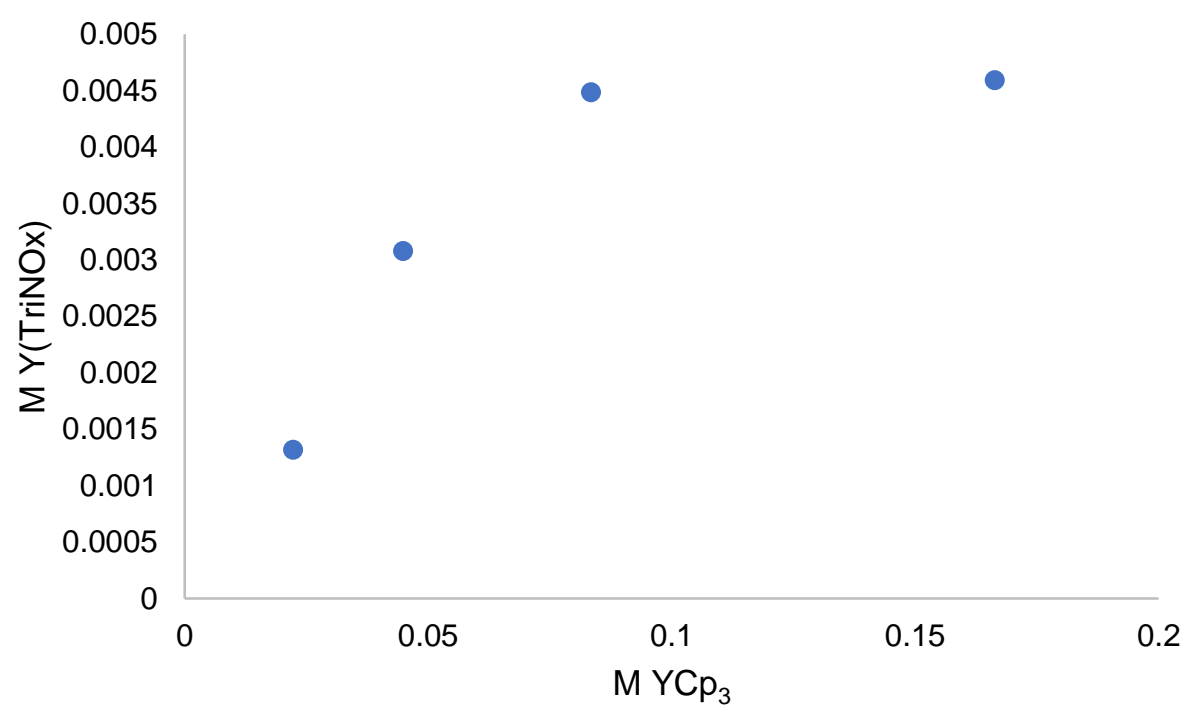

Figure S24. Variable concentration rate dependence of $Y(C p)_{3}$ for reaction with 1 at $0.5 \mathrm{~h}$.

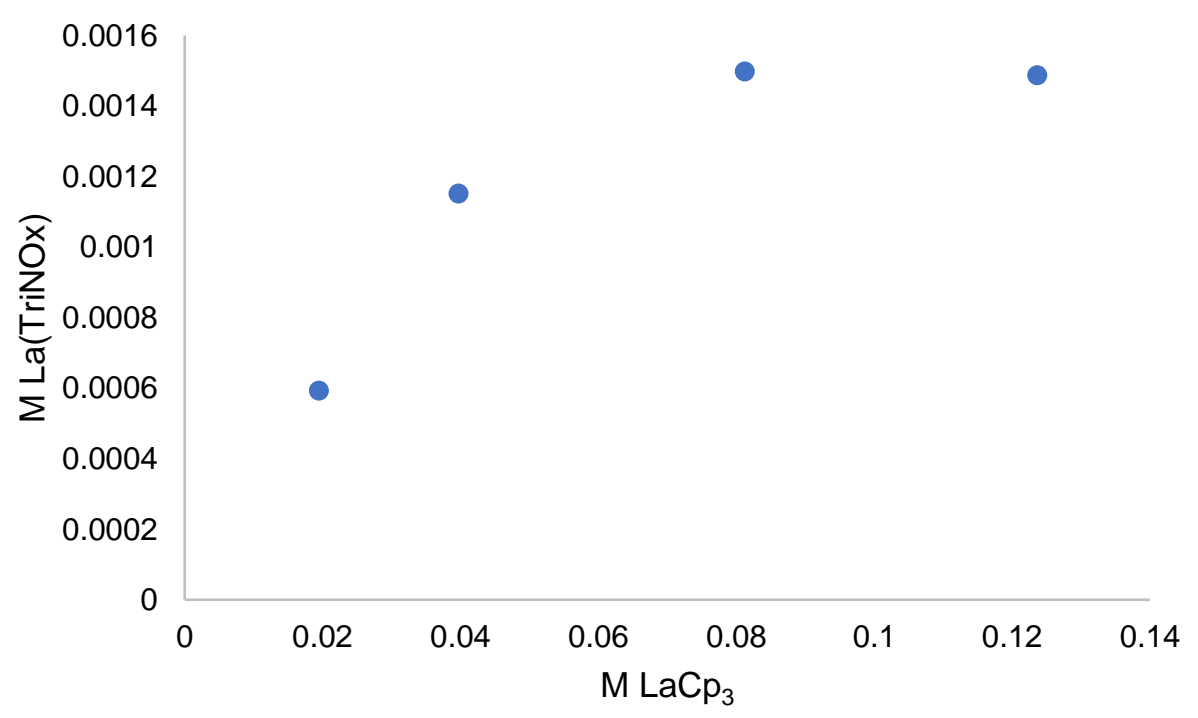

Figure S25. Variable concentration rate dependence of $L a(C p)_{3}$ for reaction with 1 at $4 \mathrm{~h}$. 


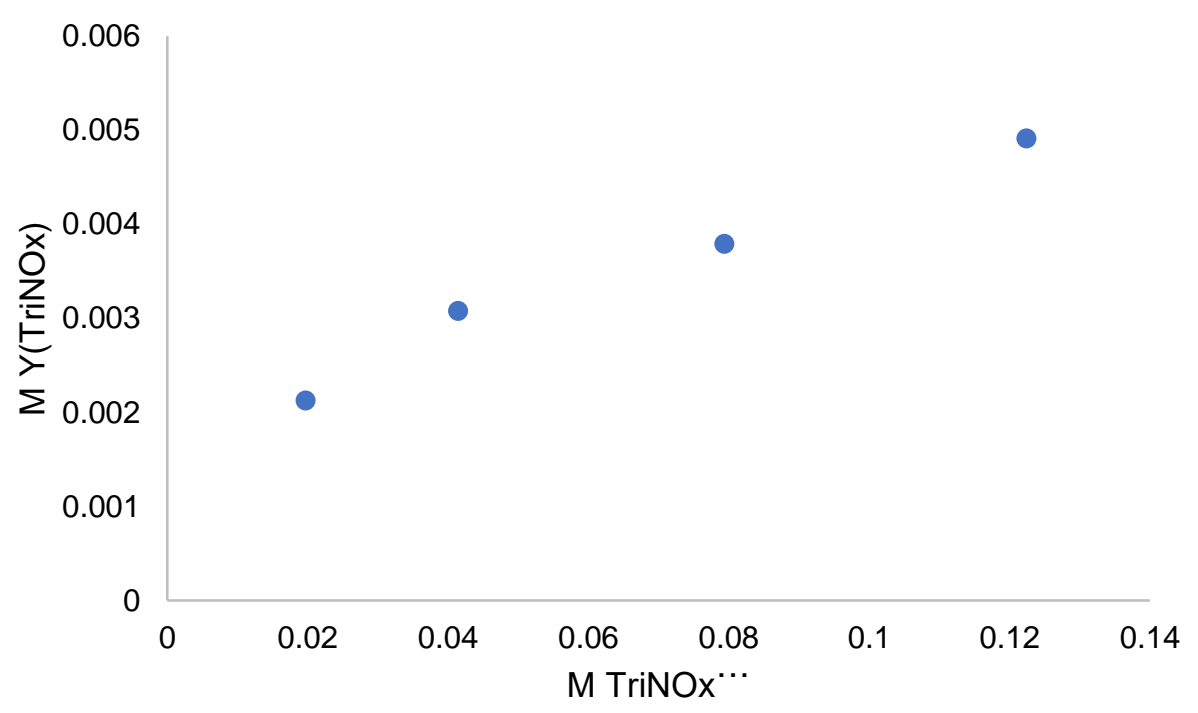

Figure S26. Variable concentration rate dependence of 1 for reaction with $Y(C p)_{3}$ at $0.5 \mathrm{~h}$.

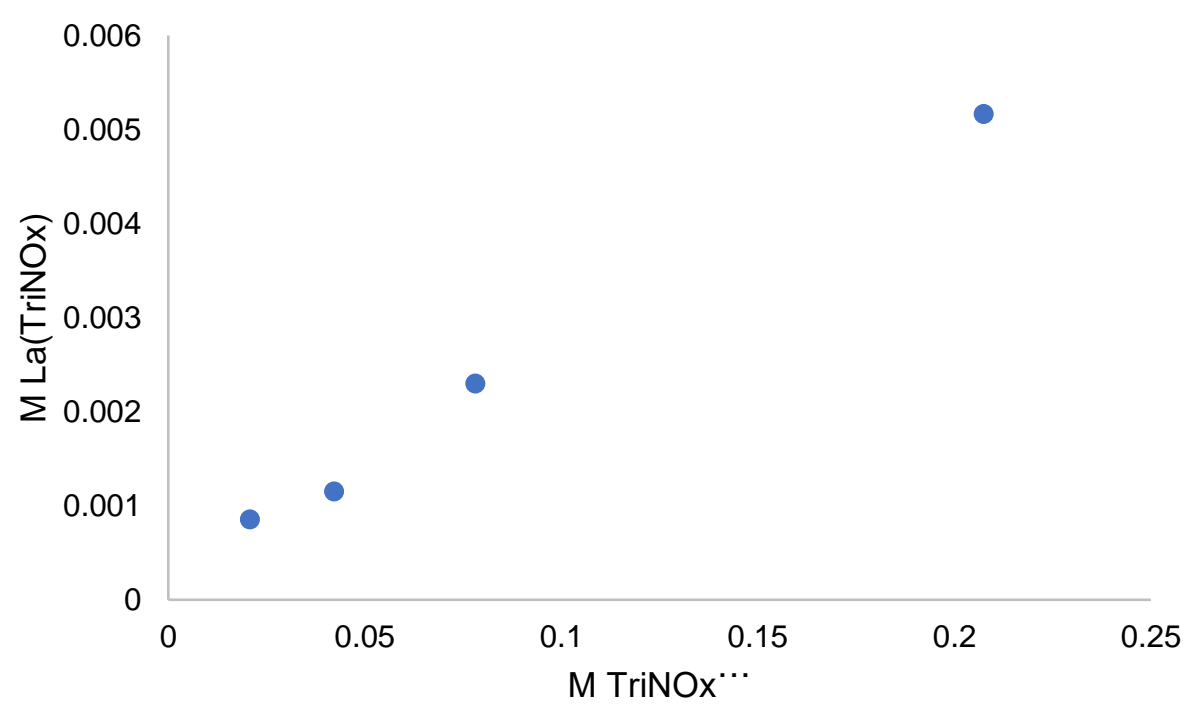

Figure S27. Variable concentration rate dependence of 1 for reaction with $\mathrm{La}(\mathrm{Cp})_{3}$ at $4 \mathrm{~h}$. 


\section{References}

1. Winge, R. K.; Peterson, V. J.; Fassel, V. A. Inductively Coupled Plasma-Atomic Emission Spectroscopy: Prominent Lines. Applied Spectroscopy 1979, 33, 206-209.

2. Parmon, V. N.; Kokorin, A. N.; Zhidomirov, G. M.; Zamaraev, K. N. On the mechanism of spin exchange in long-chain nitroxide biradicals. Mol. Phys. 1975, 30, 695.

3. Bottomley, F.; Magill, C. P.; Zhao, B. Organometallic Oxides: Oxidation of $\left(\eta-\mathrm{C}_{5} \mathrm{Me}_{5}\right)_{2} \mathrm{~V}$ with $\mathrm{O}_{2}$ To Form $\left[\left(\mu-\eta^{3}-\mathrm{C}_{5} \mathrm{Me}_{5} \mathrm{O}_{3}\right) \mathrm{V}(\mathrm{O})\right]_{2}, \quad\left[\left(\eta-\mathrm{C}_{5} \mathrm{Me}_{5}\right) \mathrm{V}\right]_{4}(\mu-\mathrm{O})_{6}$, and $\left(\eta-\mathrm{C}_{5} \mathrm{Me}_{5}\right)_{6} \mathrm{~V}_{8} \mathrm{O}_{17}$ Organometallics 1991, 10, 1946-1954. 